\title{
EDITORIAL
}

\section{EL PAPEL DE LAS AUTORIDADES SANITARIAS ANTE LOS RETOS DE LA SALUD PÚBLICA DEL SIGLO XXI *}

Juan José Francisco Polledo.

Director General de Salud Pública. Ministerio de Sanidad y Consumo.

* Conferencia dictada en el VI Congreso Derecho y Salud. Valladolid; Octubre de 1997.

Al margen de la plaga de milenarismo que, por segunda vez en la historia, está haciendo presa en la sociedad occidental, es evidente que en un futuro tan próximo como para mezclarse con nuestro presente, habrá que proceder a una reevaluación del papel de las autoridades sanitarias.

El plural incluido en el título de este trabajo («autoridades sanitarias») permitirá no tener que detenerse en diferenciar entre los diversos contenidos que el término, no unívoco, presenta cuando aparece en singular: autoridad sanitaria. Porque en el segundo supuesto, habría que aclarar si la referencia es a los órganos administrativo-políticos que son responsables de las competencias de salud pública o si, por el contrario, se refería a esa ambigua potestad pública que, imbuida de autoritas, es capaz de condicionar el libre albedrío de los ciudadanos por razones sanitarias.

No obstante, y más por eliminar confusiones con tendencia a evolucionar hacia la leyenda que por otra cosa, puede resultar conveniente dedicar unos instantes a esta segunda acepción.

Con frecuencia se habla de la autoridad sanitaria como si al hacerlo se refiriera uno a un concepto concreto de contenidos tasados y prefijados. Es más, en ocasiones se hace incluso como si se tratara de un concepto jurídico predeterminado, de cuyo contenido no hubiese la más mínima duda. Y todavía con más frecuencia, se encuentran referencias a la autoridad sanitaria como si, para lo colectivo, existiese una autoridad que se relacionara con el ciudadano igual que un médico lo hace con su paciente. Y nada de ello es cierto.

La autoridad sanitaria, así entendida en el cuerpo jurídico de un Estado de Derecho, como es España, está, por una parte , absolutamente positivada $y$, además, con frecuencia, sometida a reserva de ley.

No existe ninguna autoridad que, por razones sanitarias, pueda establecer obligaciones o prohibiciones que no hayan sido previamente descritas en los reglamentos $y$, además, cuando pueda interferirse el ámbito de las libertades individuales, se precisarán normas con rango de ley.

No deja de ser nada más que la obvia consecuencia del artículo 29.2 de la Declaración Universal de los Derechos Humanos, de 1.948 , que señala que «En el ejercicio de sus derechos y en el disfrute de sus libertades toda persona estará solamente sujeta a las limitaciones establecidas por la ley con el único fin de asegurar el reconocimiento y el respeto de los derechos y libertades de los demás, y de satisfacer las justas exigencias de la moral, del orden público y del bienestar general en una sociedad democrática».

Algo que en España tuvo muy claro el legislador cuando, en el año 1986, aprobó, 
nada menos que con el rango de orgánica, la Ley de Medidas Especiales en Materia de Salud Pública, que limita la potestad de la autoridad competente para adoptar medidas que perturben las libertades individuales a aquellas situaciones en que «se aprecien indicios racionales que permitan suponer la existencia de peligro para la salud de la población debido a la situación sanitaria concreta de una persona o grupo de personas o por las condiciones sanitarias en que se desarrolle una actividad».

Y aún la potestad construida por esta ley, habrá que presuponerla inédita en cuanto a su aplicación, no solo porque seguramente nunca se hayan producido los presupuestos que en ella se recogen, sino porque no se desarrolló la ley para dotarla de un reglamento que estableciera el procedimiento, judicial sin duda, para concretar en cada situación si concurren o no los múltiples conceptos jurídicos indeterminados que aparecen en el citado artículo $2^{\circ}$.
Y eso es la autoridad sanitaria. No menos, pero tampoco más. Algo que se deberá tener perfectamente claro cuando utilizamos el término, para evitar transmitir la sensación de que se refiere a una potestad grande pero vaga, susceptible de ser concretada puntualmente en cada momento, por criterio sanitario, por una determinada autoridad. Porque considerar las cosas a otra luz, es lo que permite que, ante determinadas situaciones, se alcen voces pidiendo lo que, presentándose como obvio, no es posible, aunque sirva para generar un clima de convencimiento de la molicie y desinterés de los responsables políticos. Y puede ser grave que esto se produzca desde la opinión pública o desde los medios de comunicación, pero más lo es que, por ignorancia, se registre también en ámbitos profesionales.

En el ámbito de la salud pública, el diagrama de flujos de la información-acción, de causas-efectos, de la valoración-decisión, es el que puede verse en la figura 1 .

Figura 1

Diagrama de los flujos causas-efectos en las políticas de salud pública

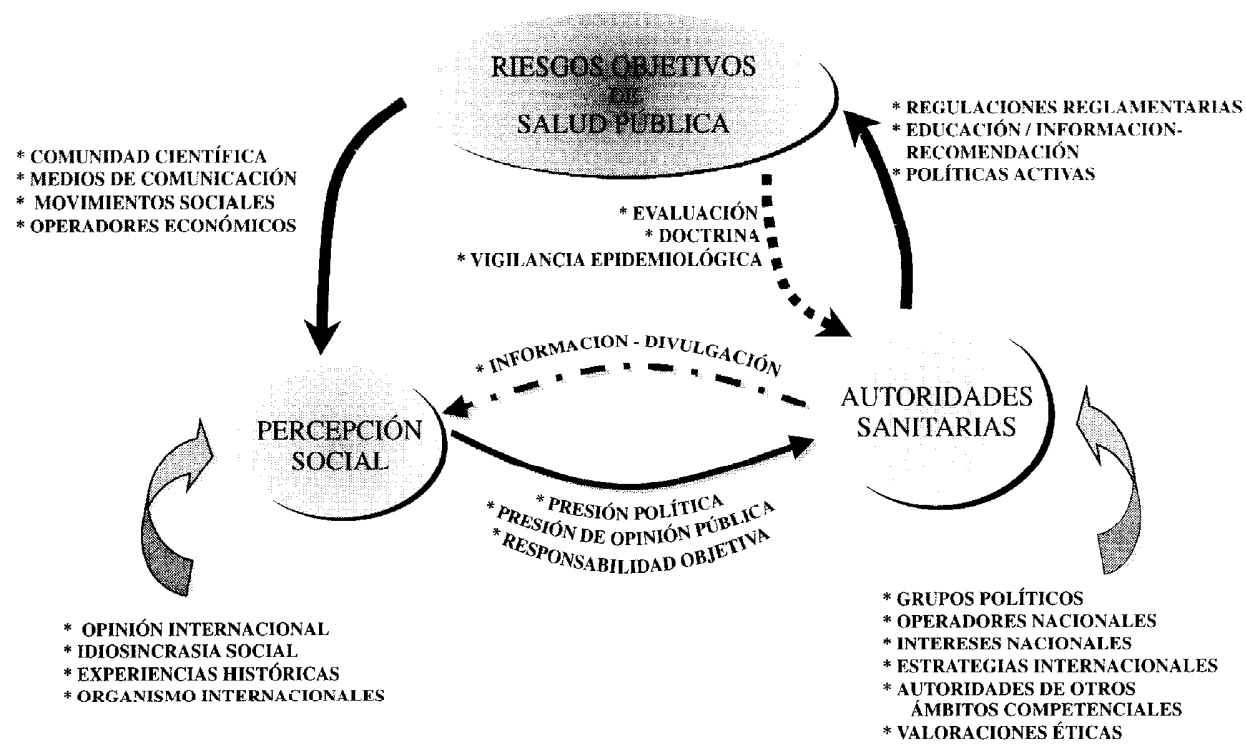


Sin ánimo de agotarlas, no resultará aventurado identificar, pronosticar, e incluso constatar, cambios en las tres variables más importantes que en ella aparecen:

$1^{\circ}$. Cambios en los problemas y riesgos objetivos de salud pública que deberán ocupar a las autoridades sanitarias del siglo XXI.

$2^{\circ}$. Modificaciones en la percepción del riesgo por parte de los ciudadanos y variaciones en sus exigencias a las autoridades sanitarias competentes.

$3^{\circ}$. Cambios substanciales e instrumentales en las propias autoridades sanitarias que van a tener que hacer frente a esos retos.

\section{Los problemas de salud pública del siglo XXI}

La de la prospectiva es una de las vías de circulación del pensamiento humano en la que se han registrado los más espectaculares accidentes; e invariablemente por error humano, pues una vez que transcurre el futuro, todo el mundo considera obvio que no podía haber sido de otra manera. Sólo unos pocos meses antes de la primera crisis del petróleo al inicio de los setenta, un prestigioso instituto internacional, después de profundos análisis, había anunciado que el factor limitante del crecimiento económico en los años inmediatos sería la escasez de cobre. Y Winston Churchill, cuando durante la segunda guerra mundial se le trataba de convencer de que destinara más medios a los servicios de previsión meteorológica, pues estaban en condiciones de alcanzar niveles de acierto del $50 \%$, contestaba que eso quería decir que tomando decisiones contrarias a las propuestas por los meteorólogos acertaría el mismo número de veces que siguiendo su consejo.

Pero no se podría desarrollar este trabajo sin tratar de vislumbrar cuales puedan ser esos nuevos retos que para la salud pública presentará el siglo XXI.
A este respecto, habría que diferenciar claramente dos campos:

1. Nuevos problemas de salud pública, fruto de nuevos factores con significado sanitario,

2. Viejos problemas de salud pública de los que se descubrirá su conexión con viejos factores.

Hacer previsiones en el primer grupo es un ejercicio ciertamente difícil que, en algunos aspectos, resulta imposible de ejecutar sin abandonar el método científico y derivar hacia la adivinanza. No obstante, existen algunas pinceladas que pueden darse ya con pulso firme:

- las nuevas sustancias químicas que se desarrollan y ponen en circulación, a pesar de los programas de seguimiento y valoración, tienen una alta potencialidad de generar problemas de salud pública.

- los cambios climáticos (cíclicos o no; naturales o inducidos; en todo caso obvios) enfrentarán a las autoridades sanitarias con problemas infecciosos de los que hasta ese momento se encontraban libres. La probabilidad de esa potencialidad se verá reforzada por las previsibles, además de seguramente deseables, corrientes migratorias.

- la enorme variedad de la demanda, la aparición de nuevas moléculas de diseño y la perdida de tradiciones y hábitos ancestrales, sustituirá el alimentarse como una operación obvia, por el alimentarse programadamente, lo que, junto a efectos heneficiosos, puede acarrear desviaciones con potencialmente graves repercusiones sanitarias,

- estupefacientes de síntesis, basados en moléculas de sencilla obtención, de enorme diversidad, y de efectos secundarios perjudiciales menos evidentes a corto plazo, podrían conducir a una percepción social más limitada del riesgo y, consecuentemente, a un incremento en su consumo, 
- nuevos alimentos junto con nuevos medicamentos, pueden protagonizar nuevas interacciones de efectos no previsibles,

- si la extensión de las resistencias antimicrobianas sigue en aumento, y más aún si se acelerara, podríamos tener que hacer frente a problemas con los que no se han tenido que enfrentar, al menos como problemas de salud pública, las últimas tres generaciones.

Y dentro del terreno de la especulación, se podrían encontrar problemas, ahora imprevisibles, fruto de las nuevas tecnologías (caso de los efectos de las radiaciones de baja intensidad), de los nuevos métodos de producción de alimentos (por ejemplo, una mala utilización de las técnicas de modificación genética), de que se alcanzasen determinados niveles de concentración para ciertos contaminantes acumulativos, de que se acceda a nuevos hábitats en los que se entre en contacto con agentes infecciosos nuevos o del debut como patógcnos de agentes que venían comportándose como saprofitos, a consecuencia de mutaciones naturales o involuntariamente inducidas.

Aún menos previsibles serían los problemas derivados del esfuerzo de adaptación que el ser humano tendrá que hacer para habitar la sociedad que se nos viene encima, o de la potencial mala utilización de las técnicas de terapia genética que en un futuro próximo pondrán, por primera vez, al hombre en manos del hombre.

Pero mucho más fructífero que este grupo resultará el segundo, el compuesto por viejos problemas de los que se descubrirán factores etiológicos o colaboradores necesarios, viejos también, que revelarán como problema algo que ahora no lo es y que se ganará el interés de las autoridades sanitarias. Aunque es difícil concretar las previsiones, no se puede apostar por otro resultado cuando se está haciendo el actual esfuerzo investigador y cuando la informática abre un tan vasto campo en los ámbitos de los sistemas de información, el manejo de la misma y el cálculo, instrumentos todos ellos de enorme repercusión para el mejor conocimiento de los problemas de salud pública.

Ios cánceres, las alergias, las enfermedades autoinmunes, las degeneraciones del sistema nervioso y otras muchas enfermedades de las que se está lejos de tener una comprensión completa, soportan la sospecha de estar, de una u otra forma, relacionadas con factores medio-ambientales que, tarde o temprano, serán desentrañados, generando nuevos focos de atención y de intervención de las autoridades sanitarias.

En todo caso, no es difícil vislumbrar algunos elementos comunes en algunos de los nuevos problemas de salud pública del siglo XXI:

1. Su capacidad de repercusión en actividades económicas,

2. El estar influidos, cuando no totalmente determinados, por las actitudes individuales de los ciudadanos,

3. ${ }^{\circ}$ Tener, frecuentemente, orígenes remotos, alejados de la capacidad de acción de quienes los sufren, y

\section{Aparecer globalizados.}

\section{La percepción del riesgo y las exigencias a las autoridades sanitarias}

A un panorama como el relatado, o como quiera que realmente acabe presentándose, habrá que hacerle frente en un ambiente social caracterizado por dos notas, éstas ya no fruto del análisis prospectivo, sino de la experiencia constatable, pues están ya presentes entre nosotros:

1. La exigencia de los ciudadanos de un riesgo cero o, al menos, mínimo, y

2. El convencimiento de que, el que cso sea así, es algo sensatamente exigible a las autoridades sanitarias. 
Y estas dos notas pueden no tener demasiada importancia en una sociedad gobernada autoritariamente, pero sí la tienen, y mucha, en una democracia.

\section{La exigencia del riesgo cero}

Sin duda es un fruto deseable propio de las sociedades desarrolladas, que valoran de forma extraordinaria la vida humana, el de considerar que todo potencial riesgo para la salud debe ser eliminado, al menos si es vulnerable y previsible.

Pero cuando esa actitud no se ve tamizada por una reflexión racional y cuando, además, se hace extensible no sólo a riesgos ciertos y demostrados sino también a aquellos que están siendo todavía debatidos en sede científica, pero que transcienden a una opinión pública hiperinformada, en esos casos, cuando concurren todas estas circunstancias, nos vemos arrastrados a situaciones en las que, fatalmente, hay que elegir entre paralizar la sociedad, tal y como se la entiende, o a asumir cotas de desprestigio y desconfianza frente a las autoridades sanitarias, que pasan a estar empañadas por una inespecífica sospecha de ineficaces o de tolerantes que ceden a intereses espúreos.

En la base de esta paradoja, que rinde una sociedad mas preocupada que nunca, mientras que los indicadores de salud mejoran y la esperanza de vida no deja de aumentar, está, sin duda, la actitud de los individuos al rechazar todo riesgo evitable, especialmente aquellos que lo son gracias a la acción de terceros, pues cuando se trata de hacer más ejercicio físico, cesar en el hábito tabáquico, moderar el consumo de alcohol o respetar escrupulosamente las reglas de circulación, las exigencias suelen ser más benévolas. Pero hay otros factores que alimentan esta deriva:

- la comunidad científica, que no siempre tiene la paciencia necesaria para esperar a publicar lo que todavía no está confirmado, de modo que, aunque para ellos esté claro, en la mente de los ciudadanos se mezcla el temor a factores de peligrosidad constatada con otros que no lo están y quizás no lo lleguen a estar nunca.

- los medios de información, sensibles a la atención que suscitan entre los ciudadanos, confieren cada vez más importancia a las informaciones relativas a posibles efectos para la salud de éste o aquel factor.

- errores históricos (sangre contaminada en Francia; «vacas locas» en Inglaterra; vino adulterado en Italia; aceite de colza en España) que dejan un poso de desconfianza para la que parece un buen antídoto el elevar las exigencias.

\section{La exigibilidad a las autoridades sanitarias}

Es la segunda característica de la actitud social frente a los riesgos para la salud. Se exige el riesgo cero y se considera que conseguirlo es una obligación de la Administración. Una teoría que no sólo sustentan los ciudadanos, sino que en sede judicial tiene la confirmación de las frecuentes exigencias de responsabilidades objetivas y que en el ámbito político, por ejemplo, ha llevado a aprobar indemnizaciones por contagios infecciosos producidos cuando todavía no se conocía la existencia de la enfermedad contagiada.

Y esta combinación está por ver si genera un incremento en los niveles de seguridad de los ciudadanos, pero lo que es indudable es que conduce, con comprensible frecuencia, a actuaciones de administración defensiva.

\section{Las autoridades sanitarias}

Tampoco resulta sencillo prever con exactitud cuales puedan ser los cambios que los próximos lustros acarrearán para las autoridades sanitarias. Pero quizás sí se esté en condiciones de aventurar algunas características que seguramente concurrirán en las autoridades sanitarias del siglo $\mathrm{xxI}$. Y, para 
este factor concreto, se debe tener en cuenta que se está haciendo referencia a las autoridades españolas, pues así como en los anteriores no, en éste, pueden existir peculiaridades propias de nuestro país.

En primer lugar, las autoridades sanitarias del futuro inmediato, tendrán una creciente dependencia e influencia de instancias internacionales, ya sean simplemente de tipo científico-asesor (caso de la OMS) o de tipo ejecutivo (entiéndase la UE o la OMS).

Las primeras influirán, principalmente, en las acciones o proyectos de los que se concretan en intervenciones directas sobre los individuos (vacunaciones, diagnósticos precoces, deshabituación tabáquica, deshabituación alcohólica, etc.). En una sociedad perfectamente informada, resultará imposible cualquier política que implique diferencias, especialmente cuando lo sean a la baja, en los niveles de protección de salud de los ciudadanos, en función del país en el que vivan, al menos en lo que se refiere al mundo desarrollado.

El segundo grupo de instancias internacionales, las de tipo ejecutivo, especialmente la Unión Europea y la Organización Mundial de la Salud, tendrán una influencia importante, y seguramente determinante, en los aspectos de salud pública que supongan acciones sobre el medio ambiente, por la repercusión que ello podría tener sobre la libre circulación de bienes y servicios. Y no se piense, a este respecto, exclusivamente en los alimentos y los medicamentos, sino que hay que hacerlo extensible a ámbitos como los servicios turísticos, las aguas (de bebida o de recreo), etc.

Una segunda circunstancia o característica de las autoridades sanitarias de los próximos años, será la de su creciente condicionamiento por la comunidad científica y sus avances. Así las cosas, habrá que pensar en unas autoridades sanitarias que habrán de acoger en su seno órganos concretos en los que ubicar, inequívocamente, la evidencia científica que oriente las decisiones políticas. Es este un proceso en el que, por ejemplo, está embarcada en estos momentos la Unión Europea, como consecuencia del análisis efectuado tras la crisis de las vacas locas.

La tercera característica previsible de las autoridades sanitarias del futuro, será la derivada de la intersectorialidad. Los avances científicos que no dejan de hallar relación entre la salud y los factores del entorno del individuo, llevan en alas a las autoridades sanitarias a tener criterio e intereses sobre aspectos cada vez mas alejados de lo que ha sido tradicionalmente su campo de acción directa. Ante esta situación, se pueden registrar dos desviaciones igualmente esterilizantes. La de que el criterio sanitario se imponga y subyugue todos los demás centros de decisión o, lo que resulta más grave, que intereses no sanitarios (económicos o no) impongan sus criterios frente a ellos. Esta tensión en el futuro no va dejar de incrementarse, y habrá que buscar soluciones políticas y de organización administrativa que sean capaces de propiciar un método de toma de decisiones y de formación de la voluntad que conjugue todos los intereses en juego.

Sometidas a una fuerte presión política, y expuestas a la solicitud de responsabilidades judicialmente, incluso por la vía penal y para personas físicas, las administraciones sanitarias del futuro, y esta sería una cuarta característica, deberán tener una prístina defini ción jurídica de sus obligaciones y de los procedimientos para cumplirlas. A este respecto, no hay ninguna razón para pensar que en el campo de la salud pública, no se siga una evolución similar a la que se registra en la asistencia sanitaria en lo referente a los errores médicos, los consentimientos informados, etc. Por esa razón, la técnica jurídica deberá desarrollar un cuerpo doctrinal en el que se determine con claridad en qué ocasiones las autoridades sanitarias, siguiendo un gradiente de más a menos intervención sobre las libertades individuales, tienen que obli- 
gar, cuando prohibir, cuando limitar, cuando aconsejar, cuando advertir, cuando informar y cuando no intervenir en absoluto. En mi consideración, no es descabellado imaginarse un futuro en el que se deba proceder a una oficial catalogación de los riesgos, en función de su gravedad y evidencia. Para ese momento, será bueno que se tenga construido el instrumento jurídico necesario que, sin duda, deberá estar inspirado en una previa reflexión ética que, de momento, se echa de menos en el campo de la salud pública.

Por último, y por lo que se refiere ya a características propias de las autoridades sanitarias en España, debemos referirnos a su fragmentación, fruto del modelo territorial del Estado, y respecto de la que no son previsibles cambios en el futuro. No soy partidario de análisis apocalípticos que pronostican grandes calamidades fruto de la convivencia de distintas autoridades con base territorial. No olvidemos que en España, como en otros países, ha habido graves problemas de salud pública cn momentos en los que el modelo político era el de un estado centralista. El escándalo de la sangre contaminada ha sido posible en un estado de centralismo napoleónico, y la encefalopatía espongiforme se le fue de las manos a un país que sólo ahora está empezando a hablar, tímidamente, de autonomías territoriales.

Pero tampoco creo que sea posible dejar de ver algunas disfunciones, quizás algunas incluso graves, fruto de la coexistencia de 17 autoridades sanitarias, con competencias plenas, y cuya coordinación suele ser entendida por cada una de ellas como la necesidad de que las demás hagan lo mismo (ni más, ni menos) que lo que ella ha decidido. Es necesario llamar la atención sobre la falacia, no siempre ingenua, de reclamar, en función de los acontecimientos, una autoridad ministerial que ponga orden. Es una buena estrategia para salir de un apuro, sirve apara atribuir al Ministerio de Sanidad y Consumo una función muy importante (la de aparecer como responsable de todos los problemas), pero es falsa. Se sabe perfectamente que la realidad jurídica es la que es, y no sirve pensar que en circunstancias especialmente graves, por arte de birlibirloque, las cosas pueden pasar automáticamente a ser de otra manera. Y lo que realmente preocupa es que en la opinión pública existe un fondo, un ruido, que alimenta esta posibilidad, y que es irresponsablemente potenciada por quien a sabiendas y desde dentro usa un discurso político que mistifica la realidad. La realidad en la distribución competencial de las autoridades sanitarias es la que se desprende del bloque constitucional, de los reales decretos de transferencias y de la Ley General de Sanidad, con las matizaciones derivadas, cuando ha habido caso, de las interpretaciones jurisprudenciales efectuadas, tanto en sede ordinaria como en la constitucional. Y si, en ocasiones, alguien piensa que esa situación, clara y sencillamente explicada al ciudadano, le escandalizaría, no es lcgítimo que le embelese con un espejismo, sino que deberá o convencerle de que sus miedos no están justificados, o de que son minoritarios o comprometerse a cambiar la realidad. No sirve definir los problemas torticeramente, a fin de que las soluciones que deseamos sean las convenientes.

Problemas objetivos de salud pública, percepción social y autoridades sanitarias, con los cambios que se ha osado pronosticar, interrelaccionándose ¿qué panorama deparan?

Yo creo, sinceramente, que optimista. Siempre que un valor, un interés, ha sido fuertemente apreciado por la sociedad, ha terminado teniendo una fuerte protección jurídica y una intensa intervención de la autoridad.

Con la salud pública ocurrirá lo mismo. Pero se deberá tencr alguna paciencia. Los avances de la ciencia nos tiene un poco perplejos y, hasta cierto punto, paralizados. No siempre somos expresamente conscientes que el objetivo de la vida no es sobrevivirla (lo cual además, por lo visto, es imposible), 
sino vivirla, y, desprovistos de una perspectiva histórica (que no puede haberla por razones obvias), rehuimos el debate social sobre la evaluación de riesgos, embarcando a toda la sociedad en la falacia de que es posible evitar todos los riesgos en todos los momentos, y que en caso de que no se haga así es porque alguien no ha cumplido con su obligación.

Por todo ello, las autoridades sanitarias que en el siglo XxI teman hacer frente a los problemas de salud pública, deberán constituirse en un verdadero brazo ejecutor de un cuerpo de doctrina inspirado en la ciencia, tamizado por las consideraciones éticas y evaluado, en algunos de sus aspectos, por una sociedad que rigurosamente informada no puede ser absolutamente exonerada de su capacidad para evaluar los riesgos.

Ese será el simple papel de la Autoridad Sanitaria en su momento, pero ahora todavía tiene el más complejo de conseguir que las cosas sean así en el futuro. 